\title{
Prediksi Kejadian Fibrilasi Atrium Paroksismal Menggunakan Jaringan Syaraf Tiruan dan Particle Swarm Optimization dengan Fitur Interval RR
}

\author{
Fahmi Alhafid, Nuryani Nuryani ${ }^{*}$, dan Darmanto Darmanto \\ Program Studi Fisika, Fakultas MIPA, Universitas Sebelas Maret, Surakarta \\ *nuryani@mipa.uns.ac.id
}

\begin{abstract}
Atrial fibrillation (AF) is the most common type of arrhythmia with an increased risk of 1.5 to 2 times that of all causes of death and increased morbidity. Paroxysmal AF (PAF) is one type of atrial fibrillation. Studies on PAF show that $20 \%-30 \%$ of individuals with AF have PAF. Research to make a PAF predictor tool model using Artificial Neural Networks (ANN) has been conducted. RR interval statistics feature is used as an input feature on the Radial Basis Function (RBF) with optimization using Particle Swarm Optimization (PSO). Electrocardiogram (ECG) data used is the Atrial Fibrillation Prediction Database (AFPDB) from PyhsioNet. With ANN output targets in the form of PAF and normal. RBF parameters that are optimized with PSO include center, width, and weight. The result of a single feature is that the PSO-RBF ANN system is better than the RBF ANN in making an FAP predictor tool model. Using variation of statistical features, a PAF prediction system is obtained with accuracy, sensitivity, and specificity of $85.82 \%, 84.15 \%$, and $87.78 \%$ respectively.
\end{abstract}

Keywords : Paroxysmal AF, RBF, PSO-RBF.

\section{ABSTRAK}

Fibrilasi Atrium (FA) merupakan jenis aritmia yang paling umum dengan peningkatan resiko 1,5 hingga 2 kali lipat dari semua penyebab kematian dan peningkatan morbiditas. FA Paroksismal (FAP) adalah salah satu tipe fibrilasi atrium. Studi mengenai FAP menunjukkan bahwa 20\% - 30\% individu dengan FA memiliki FAP. Penelitian untuk membuat model predictor tool FAP menggunakan Jaringan Syaraf Tiruan (JST) telah dilakukan. Fitur Statistik interval RR dijadikan fitur masukan pada JST Radial Basis Function (RBF) dengan optimasi menggunakan Particle Swarm Optimization (PSO). Data Elektrokardiogram (EKG) yang digunakan adalah Atrial Fibrillation Prediction Database (AFPDB) dari PyhsioNet. Dengan target keluaran JST berupa PAF dan normal. Parameter RBF yang dioptimasi dengan PSO meliputi pusat, lebar dan bobot. Hasil fitur tunggal diperoleh bahwa sistem JST PSO-RBF lebih baik jika dibandingkan dengan JST RBF dalam membuat model predictor tool FAP. Dengan variasi fitur statisitik diperoleh sistem prediksi FAP dengan akurasi, sensitivitas dan spesifitas secara berturut-turut bernilai $85,82 \%, 84,15 \%$ dan $87,78 \%$.

Kata kunci: FA Paroksismal, RBF, PSO-RBF.

\section{PENDAHULUAN}

Fibrilasi Atrium (FA) adalah kondisi yang ditandai dengan denyut jantung yang tidak teratur dan cepat, disebabkan oleh kelainan aktivitas listrik jantung ${ }^{[1]}$. Ketidakteraturan tersebut menyebabkan komplikasi yang berdampak pada timbulnya stroke dan infark miokard ${ }^{[2]}$. Prevalensi FA diperkirakan sekitar 3\% pada orang dewasa, terutama lebih tinggi pada orang tua dengan peningkatan resiko 1,5 sampai 2 kali lipat dari semua penyebab kematian dan peningkatan morbiditas, seperti stroke dan gagal jantung ${ }^{[3]}$. FA Paroksismal (FAP) adalah fibrilasi atrium yang mengalami terminasi dalam kurun waktu 48 jam, dan dapat berlanjut 
sampai 7 hari ${ }^{[4]}$. Perkiraan menunjukkan bahwa sebanyak $20 \%-30 \%$ individu yang mengalami fibrilasi atrium memiliki $\mathrm{FAP}^{[5]}$.

FAP meskipun hanya berupa episode kecil, apabila dibiarkan dan tidak tertangani maka akan mengalami FA Permanen. Hal ini berdampak pada sulitnya mengembalikan denyut jantung kembali normal. Meskipun, ada terapi sebagai solusi agar ritme jantung kembali normal ${ }^{[6]}$. Namun akan membutuhkan biaya yang tidak murah. Oleh karena itu, sistem informasi adanya kejadian FAP menjadi penting untuk dapat memberikan informasi bahwa telah terjadi FAP sehingga pasien dapat melakukan tindakan yang diperlukan. Hal ini diharapkan dapat meminimalisir terjadinya fibrilasi secara permanen.

Sistem prediksi kejadian FAP menggunakan analisis sinyal elektrokardiogram (EKG) telah dikembangkan di beberapa studi. Diantaranya oleh Chesnokov ${ }^{[7]}$, Mohebbi dan Ghassemian ${ }^{[8]}$, Boot et al ${ }^{[9]}{ }^{[10]}$ dan Narin et al ${ }^{[11]}$, dimana sinyal EKG menjadi dipakai sebagai masukan sebuah kecerdasan buatan.

Pada penelitian ini digunakan Jaringan Syaraf Tiruan (JST) dengan Radial Basis Function (RBF) dan optimasi Particle Swarm Optimization (PSO). JST adalah sistem pemrosesan data yang terdiri dari elemen pemrosesan sederhana dan saling berhubungan, yang terinspirasi oleh struktur bagian korteks serebral otak ${ }^{[12]}$. JST RBF merupakan jaringan terstruktur dengan menanamkan fungsi radial basis dalam lapisan tersembunyi dan memiliki tiga lapisan jaringan feed-forward ${ }^{[13]}$. Adapun PSO merupakan teknik komputasi evolusioner yang terinspirasi dari prilaku sosial. PSO ini merupakan algoritma yang sederhana yang efektif dalam optimasi fungsi ${ }^{[14]}$. Fitur statistik interval RR dengan segmentasi EKG 90 detik digunakan sebagai masukan pada JST untuk menentukan FAP dan normal. Kemudian metode JST RBF dan JST PSO-RBF dilakukan untuk mengkaji rancangan sistem predictor tool FAP yang menghasilkan kinerja terbaik.

\section{METODE}

Rancangan utama sistem predictor tool FAP dengan JST ditunjukkan pada Gambar 1. Data rekaman EKG yang digunakan adalah Atrial Fibrillation Prediction Database (AFPDB) dari Physionet. Dengan durasi rekaman selama 30 menit setiap rekaman, frekuensi sampel $128 \mathrm{~Hz}$. Data ini terdiri dari set pembelajaran dan set pengujian. Set pembelajaran dibagi menjadi dua bagian, yaitu bagian pertama terdiri dari 50 rekaman yang berasal 50 pasien normal. Bagian kedua terdiri dari 50 rekaman yang mempunyai catatan FA Paroksismal (FAP) yang berasal dari 48 pasien $^{[15]}$.

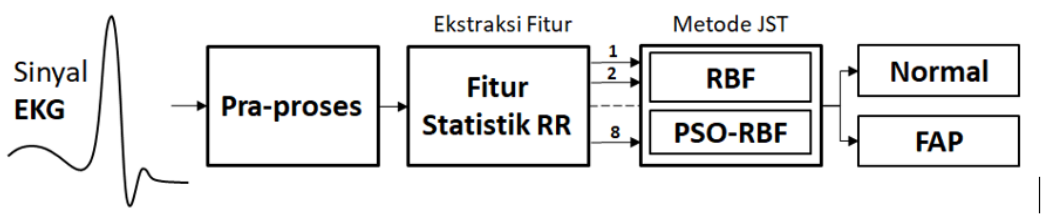

Gambar 1. Rancangan Sistem

Pada penelitian ini bahan yang digunakan adalah rekaman FAP yang terdiri dari dua kategori. Kategori pertama yaitu FAP distant (sebanyak 25 rekaman) dimana selama 45 menit sebelum dan sesudah rekaman tidak terjadi FAP. Kategori kedua yaitu FAP preceding (sebanyak 24 rekaman) yang merupakan rekaman 30 menit sebelum terjadinya FAP. Kedua kategori ini diolah dengan metode JST menggunakan perangkat lunak MATLAB. Target keluaran yang diharapkan berupa normal (untuk kategori distant FAP) dan FAP (untuk kategori FAP preceding). 
Pada EKG dilakukan tahapan pra-proses. Tujuan pra-proses untuk melemahkan noise pada sinyal EKG serta mengurangi kesalahan deteksi puncak R. Algoritma Pan-Tompkins digunakan untuk menentukan puncak $\mathrm{R}$ dan sekaligus untuk filtrasi menggunakan bandpass filter $^{[16]}$. Selanjutnya tahapan ekstraksi fitur digunakan untuk memperoleh nilai-nilai fitur statistik RR. Adapun fitur yang digunakan meliputi Mean $\mathrm{RR}\left(\mathrm{RR}_{\text {mean }}\right)$, Root Mean Squared $\mathrm{RR}\left(\mathrm{RR}_{r m s}\right)$, Geometric Mean RR (RR gmean $)$, Harmonic Mean RR $\left(R_{\text {hmean }}\right)$, Varians $\mathrm{RR}$ $\left(\mathrm{RR}_{\text {var }}\right)$, Standard Deviation RR ( $\left.\mathrm{RR}_{s t}\right)$, Maximal $\mathrm{RR}\left(\mathrm{RR}_{\text {max }}\right)$, dan Minimal RR $\left(\mathrm{RR}_{\text {min }}\right)$. Tahapan pada ekstraksi fitur meliputi segmentasi 90 detik, perhitungan interval RR, perhitungan statistik RR, normalisasi dan randomisasi. Hasil dari ekstrasi fitur ini kemudian menjadi masukan pada JST.

Tahapan pada sistem JST terbagi kedalam 2 tahapan, yaitu tahap pelatihan dan tahap pengujian. Data pelatihan yang digunakan sebanyak $80 \%$ dari total keseluruhan data, sedangkan data pengujian sebanyak $20 \%$ dari total keseluruhan data, dengan validasi sistem menggunakan metode 5-fold cross validation. Target keluran JST RBF mengikuti Persamaan 1, dengan fungsi aktivasi radial basis menggunakan fungsi gaussian seperti pada Persamaan $2^{[13]}$.

$$
\begin{aligned}
& y_{j}(i)=\sum_{k=1}^{K} w_{j k} \Phi\left[\left(x(i), c_{k}, \sigma_{k}\right)\right] \\
& \Phi\left(x_{i}, c_{k i}, \sigma_{k i}\right)=\exp \left(-\frac{\left(x_{i}-c_{k i}\right)^{2}}{2 \sigma_{k i}^{2}}\right)
\end{aligned}
$$

dimana :

$$
\begin{aligned}
& \mathrm{j}=1,2, \ldots \mathrm{n} \\
& \mathrm{n}=\text { jumlah } \text { nodes keluaran pada lapisan keluaran } \\
& \mathrm{i}=1,2, \ldots \mathrm{N} \\
& \mathrm{N}=\text { Jumlah nodes masukan pada lapisan masukkan } \\
& \mathrm{K}=\text { Jumlah neuron } \mathrm{RBF} \\
& C_{k} \in R^{m} \text { dan } \sigma_{k} \in R^{m}=\text { Nilai vektor pusat dan lebar RBF } \\
& \left\{w_{j k} \mid \mathrm{k}=1,2, \ldots \mathrm{K}\right\}=\text { Bobot RBF yang terhubung dengan keluaran ke-j }
\end{aligned}
$$

Ada tiga jenis parameter dalam model RBF dengan fungsi basis Gaussian ini, yaitu : pusat (neuron lapisan tersembunyi), lebar (standar deviasi dalam kasus RBF Gaussian); dan bobot lapisan keluaran ${ }^{[13]}$. Ketiga parameter tersebut digunakan sebagai inisialisasi parameter awal dalam PSO. Dengan persamaan update kecepatan dan posisi partikel PSO $^{[17]}$ yaitu sebagai berikut :

$$
\begin{aligned}
& V_{i d}(t+1)=w \times V_{i d}(t)+c_{1} r_{1}\left(P_{i d}(t)-X_{i d}(t)\right)+c_{2} r_{2}\left(P_{g d}(t)-X_{i d}(t)\right) \\
& X_{i d}(t+1)=X_{i d}(t)+V_{i d}(t+1) \\
& \mathrm{i}=1,2, \ldots \mathrm{M} ; \mathrm{d}=1,2, \ldots \mathrm{n}
\end{aligned}
$$

dengan $w$ adalah bobot inersia, $c_{1}$ dan $c_{2}$ adalah koefisien percepatan. Vektor $P_{i}=$ $\left(P_{i 1}, P_{i 2}, \ldots P_{i n}\right)$ adalah posisi partikel terbaik sebelumnya (posisi yang memberikan nilai fitness terbaik) dari partikel $i$, disebut juga sebagai personal best position (pBest). Vektor $P_{g}=\left(P_{g 1}, P_{g 2}, \ldots P_{g n}\right)$ adalah posisi terbaik diantara $p$ Best dari partikel dalam populasi, disebut juga sebagai global best positions (gBest). Parameter $r_{1}$ dan $r_{2}$ adalah angka acak dalam rentang $(0,1)$. Nilai $V_{i d}$, nilai yang dibatasi dalam interval $\left[-V_{\max }, V_{\max }\right]$. 


\section{HASIL DAN PEMBAHASAN}

Hasil dari ekstraksi fitur menunjukkan bahwa untuk kategori FAP memiliki 57.204 denyut sedangkan untuk kategori normal sebanyak 58.828 denyut. Untuk analisis distribusi hasil ekstraksi fitur menggunakan box plot seperti pada Gambar 2. Tujuan penggunaan box plot untuk membandingkan kumpulan data yang saling berkaitan. Nilai kuartil atas dan kuartil bawah menjadi penentu batas persegi panjang, dan garis horizontal yang memotong persegi panjang tersebut merupakan median dari data ${ }^{[18]}$.
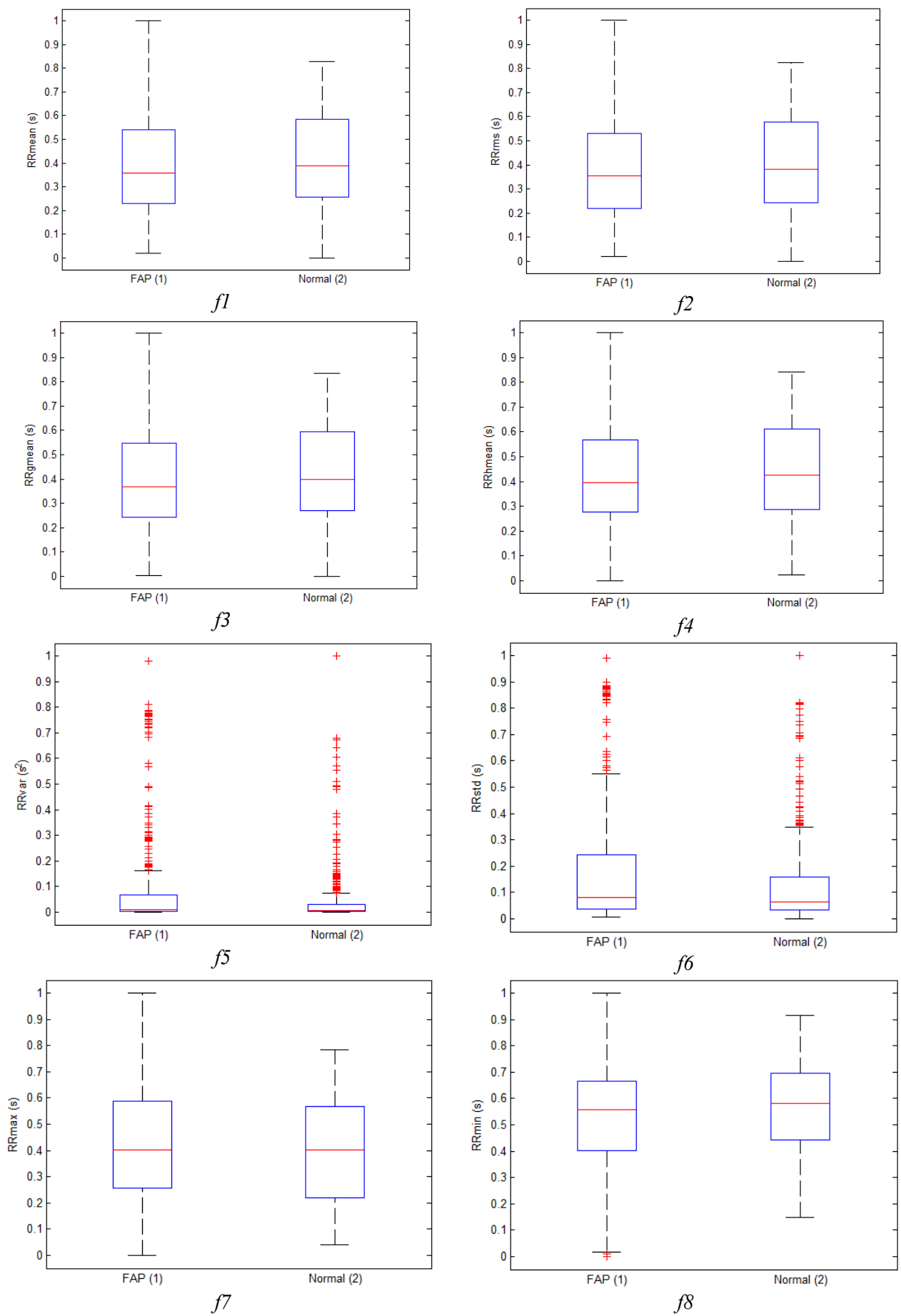

Gambar 2. Box plot fitur statistik RR (f1- $f 8)$. 
Berdasarkan Gambar 2 terlihat perbedaan distribusi data, dimana fitur pada FAP secara umum memiliki posisi yang lebih rendah dibandingkan dengan keadaan normal. Fitur FAP yang posisinya lebih rendah meliputi fitur $f 1, f 2, f 3, f 4$ dan $f 8$. Hal ini juga diperkuat dengan nilai median-nya pada Tabel 1 yang lebih rendah dari keadaan normal. Fitur $f 5, f 6$ dan $f 7$ pada FAP bernilai lebih tinggi dari posisi normalnya. Perbedaan-perbedaaan ini kemudian menjadi dasar masukan JST dalam dalam mencari model predictor tool FAP terbaik.

Tabel 1. Nilai median box plot fitur statistik RR

\begin{tabular}{clcc}
\hline \multirow{2}{*}{ Fitur } & \multirow{2}{*}{ Keterangan Fitur Statitik RR } & \multicolumn{2}{c}{ Nilai Median } \\
\cline { 3 - 4 } & & FAP & Normal \\
\hline$f 1$ & Mean RR $\left(R R_{\text {mean }}\right)(\mathrm{s})$ & 0,36 & 0,39 \\
$f 2$ & Root Mean Squared RR $\left(R R_{\text {rms }}\right)(\mathrm{s})$ & 0,35 & 0,38 \\
$f 3$ & Geometric Mean RR $\left(R R_{\text {gmean }}\right)(\mathrm{s})$ & 0,37 & 0,40 \\
$f 4$ & Harmonic Mean RR $\left(R R_{\text {hmean }}\right)(\mathrm{s})$ & 0,40 & 0,42 \\
$f 5$ & Varians $\mathrm{RR}\left(R R_{\text {var }}\right)\left(\mathrm{s}^{2}\right)$ & 0,01 & 0,01 \\
$f 6$ & Standard Deviation RR $\left(R R_{\text {std }}\right)(\mathrm{s})$ & 0,08 & 0,06 \\
$f 7$ & Maximal RR $\left(R R_{\max }\right)(\mathrm{s})$ & 0,40 & 0,40 \\
$f 8$ & Minimal RR $\left(R R_{\min }\right)(\mathrm{s})$ & 0,56 & 0,58 \\
\hline
\end{tabular}

Kondisi FAP memiliki rata-rata interval RR yang lebih kecil dibandingkan dengan kondisi normalnya. Hal ini karena adanya ketidakteraturan aktivitas listrik jantung ${ }^{[1]}$. Sinyal-sinyal listrik yang ada di atrium tidak terorganisir, menyebabkan kontraksi yang sangat cepat dan fibrilasi (tidak teratur). Akibatnya darah yang seharusnya dipompa ke ventrikel malah berkumpul di atrium. Hal ini ditandai dengan detak jantung yang sangat cepat sehingga kemunculan gelombang P tidak dapat dilihat ${ }^{[19]}$. Ini mengakibatkan jarak antara puncak $\mathrm{R}$ dengan puncak R sebelumnya didalam ritme FAP menjadi lebih sempit.

Hasil ekstraksi fitur kemudian menjadi masukan pada JST RBF dan PSO-RBF, dengan arsitektur RBF seperti pada Gambar 3. Berdasarkan penelitian Anzihory et al ${ }^{[19]}$ dalam membedakan FA dengan keadaan normal, diperoleh bahwa model RBF mampu menghasilkan kinerja yang lebih baik dibandingkan dengan model Learning Vector Quantization (LVQ) dan Multilayer Perception (MLP). Serta dalam penelitian Maftukhaturrizqoh et al ${ }^{[20]}$ dalam mendeteksi kantuk menggunakan JST RBF menghasilkan kinerja yang cukup baik dalam membedakan keadaan mengantuk dengan kondisi terjaga.

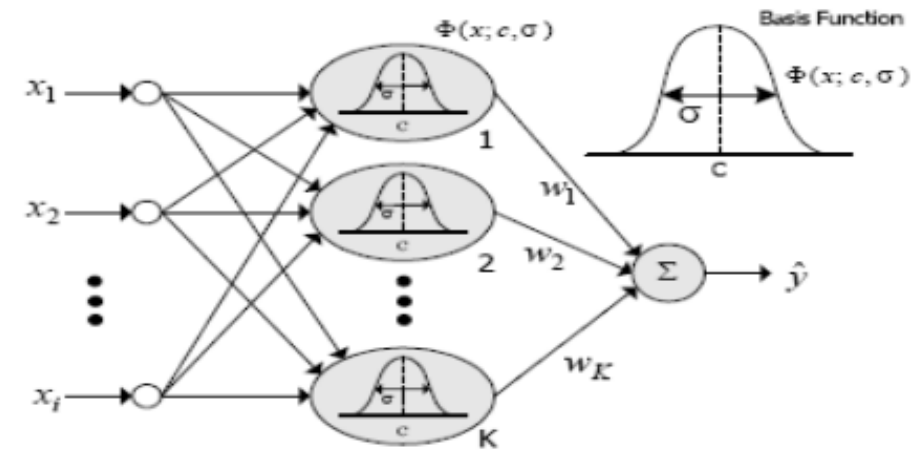

Gambar 3. Arsitektur JST RBF ${ }^{[13]}$. 
Parameter yang dioptimasi meliputi 3 parameter $\mathrm{RBF}^{[13]}$, yaitu pusat, dan lebar pada lapisan tersembunyi, serta bobot diantara lapisan tersembunyi dan lapisan keluaran. Tujuan dari optimasi menggunakan PSO supaya mendapat parameter RBF yang mampu menghasilkan kinerja yang lebih baik lagi. Hasil yang diperoleh ditunjukkan oleh Gambar 4 yang merupakan perbandingan akurasi antara JST RBF dengan JST PSO-RBF untuk masing masing fitur (fitur tunggal). Akurasi yang diperoleh setelah dioptimasi, sangat signifikan meningkat drastis kecuali pada fitur $f 8$ yang hanya sedikit menaikkan akurasinya.

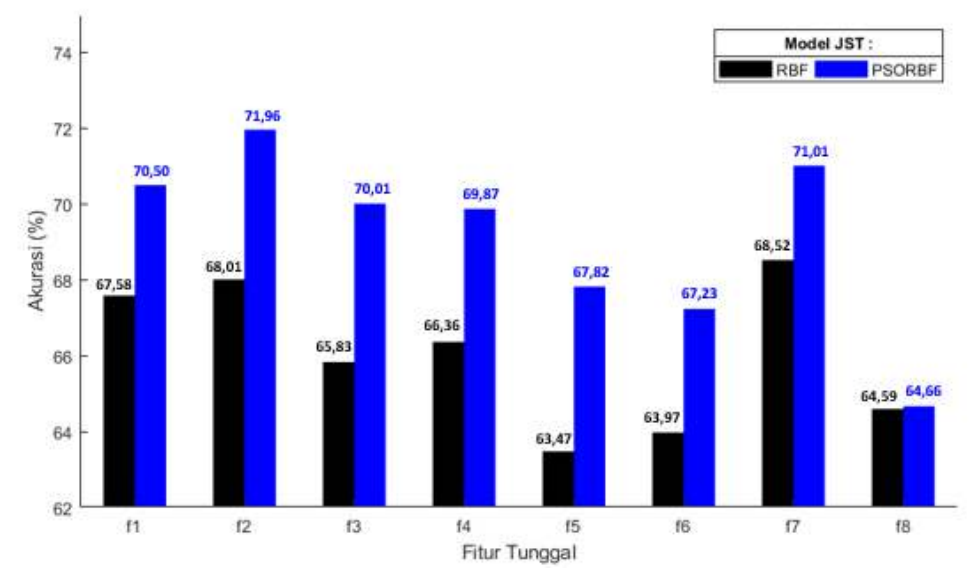

Gambar 4. Bar plot perbandingan akurasi JST RBF dengan JST PSO-RBF terhadap fitur tunggal.

Untuk mendapatkan kinerja yang lebih baik, masukan pada JST dilakukan variasi fitur dengan mengkombinasikan fitur tunggal berdasarkan urutan akurasi yang terbaik. Kinerja dari hasil pelatihan dan pengujian dihitung berdasarkan persamaan sebagai berikut :

$$
\begin{aligned}
& \text { Akurasi (\%) }=\frac{\mathrm{TP}+\mathrm{TN}}{\mathrm{TP}+\mathrm{TN}+\mathrm{FP}+\mathrm{FN}} \times 100 \\
& \text { Sensitivitas (\%) }=\frac{\mathrm{TP}}{\mathrm{TP}+\mathrm{FN}} \times 100 \\
& \text { Spesifitas (\%) }=\frac{\mathrm{TN}}{\mathrm{TN}+\mathrm{FP}} \times 100
\end{aligned}
$$

dimana TP (True Positive) adalah jumlah ketika FAP terdeteksi dengan benar, FP (False Positive) adalah jumlah ketika normal terdeteksi salah, FN (False Negative) adalah jumlah ketika FAP terdeteksi salah, dan TN (True Negative) adalah jumlah ketika Normal terdeteksi benar.

Dengan ketiga persamaan tersebut diperoleh hasil variasi kombinasi fitur yang ditunjukkan pada Tabel 2. Hasil terbaik ditunjukkan dengan kinerja JST PSO-RBF pada variasi delapan macam kombinasi fitur $(k f 8)$ dengan akurasi, sensitivitas dan spesifitas secara berturut-turut bernilai $85,82 \%, 84,15 \%$ dan $87,78 \%$. 
Tabel 2. Kinerja JST PSO-RBF pada variasi kombinasi fitur

\begin{tabular}{lccc}
\hline \multicolumn{1}{c}{ Kombinasi Fitur } & Akurasi (\%) & Sensitivitas (\%) & Spesifitas (\%) \\
\hline$f 2$ & 69,85 & 69,14 & 70,76 \\
$f 2, f 7$ & 74,30 & 71,68 & 77,16 \\
$f 2, f 7, f 1$ & 75,37 & 73,17 & 77,75 \\
$f 2, f 7, f 1, f 3$ & 75,34 & 73,29 & 77,57 \\
$f 2, f 7, f 1, f 3, f 4$ & 81,61 & 81,40 & 82,18 \\
$f 2, f 7, f 1, f 3, f 4, f 5$ & 83,23 & 83,32 & 83,28 \\
$f 2, f 7, f 1, f 3, f 4, f 5, f 6$ & 84,66 & 85,66 & 83,76 \\
$f 2, f 7, f 1, f 3, f 4, f 5, f 6$, & 85,82 & 84,15 & 87,78 \\
$f 8$ & & & \\
\hline
\end{tabular}

\section{KESIMPULAN}

Pada penelitian ini telah dibuat rancangan sistem predictor tool FAP menggunakan fitur statistik RR dengan metode JST, yaitu JST PSO-RBF dan JST RBF. Hasil ekstraksi fitur sebanyak 8 fitur statistik interval RR menjadi fitur masukan JST dengan variasi segmentasi 90 detik. Kinerja sistem prediski dengan fitur tunggal menggunakan JST PSO-RBF lebih baik jika dibandingkan dengan JST-RBF dalam membuat model predictor tool FAP. Hasil terbaik JST PSO-RBF diperoleh saat delapan fitur diigunakan semua, yaitu dengan akurasi, sensitivitas dan spesifitas secara berturut-turut bernilai 85,82\%, 84,15\% dan 87,78\%.

\section{DAFTAR PUSTAKA}

1 Gotlibovych, I., Crawford, S., Goyal, D., Liu, J., Kerem, Y., Benaron, D., Yilmaz, D., Marcus, G., \& Li, Y. 2018. End-to-end Deep Learning from Raw Sensor Data: Atrial Fibrillation Detection using Wearables. arXiv preprint arXiv. 1807.1070.

2 Xu, X., Wei, S., Ma, C., Luo, K., Zhang, L., \& Liu, C. 2018. Atrial fibrillation beat identification using the combination of modified frequency slice wavelet transform and convolutional neural networks. Journal of Healthcare Engineering.

3 Outes, G.A., Suárez-Gea, M. L., \& García-Pinilla, J. M. 2017. Causes of death in atrial fibrillation: Challenges and opportunities. Trends in Cardiovascular Medicine, 27(7), 494-503.

4 Camm, A. J., Kirchhof, P., Lip, G. Y. H., Schotten, U., Savelieva, I., Ernst, S., ... ESC Committee for Practice Guidelines. 2010. Guidelines for the management of atrial fibrillation: the Task Force for the Management of Atrial Fibrillation of the European Society of Cardiology (ESC). Europace : European Pacing, Arrhythmias, and Cardiac Electrophysiology: Journal of the Working Groups on Cardiac Pacing, Arrhythmias, and Cardiac Cellular Electrophysiology of the European Society of Cardiology, 12(10), $1360-1420$.

5 Zoni-Berisso, M., Lercari, F., Carazza, T., \& Domenicucci, S. 2014. Epidemiology of atrial fibrillation: European perspective. Clinical epidemiology, 6, 213-220.

6 Al-Khatib, S. M., Wilkinson, W. E., Sanders, L. L., McCarthy, E. A., \& Pritchett, E. L. 2000. Observations on the transition from intermittent to permanent atrial fibrillation. American heart journal, 140(1), 142-145. 
7 Chesnokov, Y. V. 2008. Complexity and spectral analysis of the heart rate variability dynamics for distant prediction of paroxysmal atrial fibrillation with artificial intelligence methods. Artificial Intelligence in Medicine, 43(2), 151-165.

8 Mohebbi, M., \& Ghassemian, H. 2012. Prediction of paroxysmal atrial fibrillation based on non-linear analysis and spectrum and bispectrum features of the heart rate variability signal. Computer methods and programs in biomedicine, 105(1), 40-49.

9 Boon, K. H., Khalil-Hani, M., Malarvili, M. B., \& Sia, C. W. 2016. Paroxysmal atrial fibrillation prediction method with shorter HRV sequences. Computer methods and programs in biomedicine, 134, 187-196.

10 Boon, K. H., Khalil-Hani, M., \& Malarvili, M. B. 2018. Paroxysmal atrial fibrillation prediction based on HRV analysis and non-dominated sorting genetic algorithm III. Computer methods and programs in biomedicine, 153, 171-184.

11 Narin, A., Isler, Y., Ozer, M., \& Perc, M. 2018. Early prediction of paroxysmal atrial fibrillation based on short-term heart rate variability. Physica A: Statistical Mechanics and its Applications, 509, 56-65.

12 Uhrig, R. E. 1995. Introduction to artificial neural networks. In Proceedings of IECON'95-21st Annual Conference on IEEE Industrial Electronics, (1), 33-37.

13 Qasem, S. N., \& Shamsuddin, S. M. H. 2009. Improving performance of radial basis function network based with particle swarm optimization. In 2009 IEEE Congress on Evolutionary Computation, 3149-3156.

14 Kennedy, J and Eberhart,R.C. 1995 .Particle Swarm Optimization, Proceedings of IEEE International Conference on Neural Networks, IV. Piscataway, 1942-1948.

15 Goldberger A.L., Amaral, L.A.N., Glass, L., Hausdorff, J.M., Ivanov, P.C.h., Mark, R.G., Mietus, J.E., Moody, G.B., Peng, C-K., Stanley, H.E. 2000. PhysioBank, PhysioToolkit, and PhysioNet: Components of a New Research Resource for Complex Physiologic Signals. Circulation, 101(23), 215-220.

16 Pan, J. and Tompkins, W. J. 1985. A real-time QRS detection algorithm. IEEE Trans. Biomed. Eng. BME-32: 230-36,

17 Shi, Y., \& Eberhart, R. 1998. A modified particle swarm optimizer. In 1998 IEEE international conference on evolutionary computation proceedings. IEEE world congress on computational intelligence (Cat. No. 98TH8360), 69-73.

18 Farosi, K., Nuryani, N., \& Darmanto, D. 2017. Optimasi Fuzzy Inference System pada Sistem Deteksi Fibrilasi Atrium dengan Fitur Elektrokardiogram. Jurnal Fisika Dan Aplikasinya, 13(1), 10-13.

19 Anzihory, E., Nuryani, N., \& Darmanto, D. 2016. Sistem Deteksi Fibrilasi Atrium menggunakan Fitur RR Elektokardiogram dengan Jaringan Syaraf Tiruan. Jurnal Fisika dan Aplikasinya, 12(2), 57-60.

20 Maftukhaturrizqoh, O., Nuryani, N., \& Darmanto, D. 2019. Drowsiness detection using radial basis function network with electrocardiographic RR interval statistical feature. In Journal of Physics: Conference Series, 1153(1), 012049 